\title{
$\operatorname{movim}_{\text {revistade }}$ educaco
}

faculdade de educação - programa de pós-graduação em educação

universidade federal fluminense

issn 2359-3296

ano 3 número 4 - 2016

\section{CURRÍCULOS ESCOLARES: saberes docentes na produção de materiais didáticos por professores da educação básica}

\author{
Bianca Gonçalves Sousa de Moraes ${ }^{1}$ \\ Natalia Collares de Moura da Rocha² \\ Maria Margarida Gomes ${ }^{3}$
}

\section{RESUMO}

O presente artigo tem como principal objetivo compreender possíveis articulações entre os processos de produção de materiais didáticos elaborados e/ou utilizados por professores (as) da educação básica e seus saberes docentes. As análises empreendidas reforçam a ideia de que os saberes docentes são múltiplos e personalizados, refletindo a trajetória de vida, acadêmica e profissional, e permitindo a construção do ser docente de cada um. É notório o quanto esses saberes interferem no currículo escolar, já que levam a valorização de diferentes e novas abordagens curriculares que são concretizadas nos materiais didáticos.

Palavras-chave: Currículos escolares; materiais didáticos; saberes docentes.

\section{ABStRACT}

This article aims to understand possible links between the developed educational materials and/or its use by basic education teachers and their teaching knowledge. The analysis undertaken reinforce the idea that teaching knowledge are multiple and customized, reflecting the trajectory of life, academic and professional, and allowing the

1 Doutoranda em Educação da Universidade Federal do Rio de Janeiro (PPGE/UFRJ). Endereço eletrônico: biasousa04@yahoo.com.br.

2 Mestre em Educação pela Universidade Federal do Rio de Janeiro (PPGE/UFRJ). Endereço eletrônico: nataliacollares@gmail.com.

${ }^{3}$ Professora Adjunta do Departamento de Didática da Faculdade de Educação e do Programa de Pós-Graduação em Educação da Universidade Federal do Rio de Janeiro (PPGE/UFRJ.

Endereço eletrônico: margaridaplgomes@gmail.com 
construction of being a teacher. It is clear how this knowledge interfere in the school curriculum, as lead to appreciation of different and new curricular approaches which can be observed in teaching materials.

Key-words: School Curriculum; Teaching Materials; Teaching Knowledge.

\section{INTRODUÇÃO}

Nesse trabalho focamos em materiais didáticos elaborados e/ou utilizados por professores (as) da educação básica, investindo especificamente na compreensão de articulações entre os processos de produção de tais materiais e os saberes docentes. As reflexões aqui apresentadas associam e ampliam a análise dos resultados produzidos em duas dissertações de mestrado4, associando-a com as discussões empreendidas no grupo de estudos "currículos escolares, ensino de Ciências e materiais didáticos" 5 . Trata-se de uma pesquisa situada no campo de estudos do currículo cujo interesse reside, especialmente, em compreender a relação entre os saberes docentes e a produção de materiais didáticos, refletindo também sobre possíveis influências que isso provoca sobre o currículo das disciplinas escolares.

Os materiais didáticos e depoimentos dos (as) professores (as) são aqui analisados considerando-se a organização disciplinar na qual se inserem e são produzidos, além das características próprias dos saberes docentes. Assim, nossas análises têm como base os estudos sobre os saberes docentes de Maurice Tardif $(2000 ; 2012)$ e Maurice Tardif e Danielle Raymond (2000) buscando interpretar suas especificidades em meio a todas as decisões tomadas pelos (as) professores (as) nas ações cotidianas do exercício de sua profissão. Além disso, também buscamos compreender os saberes docentes em meio à estrutura de organização e produção dos currículos escolares. Para

\footnotetext{
${ }^{4}$ As dissertações que nos referimos são intituladas "Materiais didáticos como 'inovações' curriculares: entre saberes docentes e 'tradições' da Disciplina Escolar Ciências" e "Currículos escolares: a articulação de saberes em práticas de educação ambiental"

${ }^{5}$ O grupo é parte do Núcleo de Estudos de Currículo da Faculdade de Educação da Universidade Federal do Rio de Janeiro (NEC/UFRJ) e é coordenado pela Profa. Dra. Maria Margarida Gomes
} 
tal, nos apoiamos nos estudos relacionados às disciplinas escolares de André Chervel (1990) e Ivor Goodson (1997; 2012) que nos permitem olhar para as produções curriculares dos (as) professores (as) como específicas de uma forma de agir e produzir saberes da docência em contextos escolares.

Na próxima seção são apresentados os principais aspectos da abordagem teórico-metodológica que orientam a análise e compreensão dos saberes envolvidos na produção de materiais didáticos por professores (as) da educação básica. Em seguida, trechos de depoimentos, sobre a produção e utilização de materiais didáticos pelos (as) professores (as), são analisados explicitando as dinâmicas de seus saberes. Por fim, são tecidas as considerações finais.

Perspectivas de ANÁlise: saberes docentes em meio às dinâmicas das disciplinas escolares

Como já indicado, este trabalho se utiliza de dados coletados para a produção de trabalhos anteriores (MORAES, 2015; MOURA, 2015). As fontes para tais dados são dois grupos de professores (as) que atuam na educação básica: professoras de Ciências do Colégio de Aplicação da UFRJ (CAp/UFRJ)6; e professores (as) ${ }^{7}$ de Biologia, História e Geografia que participaram da primeira versão do Curso de Form-Ação em Educação Ambiental e Agenda 21 Escolar: Elos de Cidadania ${ }^{8}$. Nesse sentido, foram realizadas entrevistas

\footnotetext{
${ }^{6}$ A coleta de dados a partir dessas professoras foi realizada para a produção da dissertação intitulada "Materiais didáticos como 'inovações' curriculares: entre saberes docentes e 'tradições' da Disciplina Escolar Ciências", na qual é apresentada uma investigação sobre 'inovações'/tradições curriculares presentes em materiais didáticos produzidos por professoras de Ciências do CAp/UFRJ, esclarecendo de que forma os saberes docentes se relacionam com a produção das 'inovações' curriculares.

7 A coleta de dados a partir desses (as) professores (as) foi realizada para a produção da dissertação intitulada "Currículos escolares: a articulação de saberes em práticas de educação ambiental", na qual é apresentada uma investigação relacionadas às ações de EA; à sua seleção e inserção no currículo escolar; aos sujeitos envolvidos no planejamento e realização dessas ações; às áreas disciplinares envolvidas; à articulação de saberes para a produção dessas ações; as dificuldades encontradas e à contribuição da formação continuada em EA.

${ }^{8} \mathrm{O}$ curso foi uma parceria da Universidade do Estado do Rio de Janeiro (UERJ) com a Secretaria de Estado de Educação (SEEDUC); Secretaria de Estado do Ambiente (SEA); Secretaria de Ciências e Tecnologia (SECT), e foi financiado pelo Fundo Estadual de Conservação Ambiental e Desenvolvimento Urbano (FECAM/RJ). Teve como objetivo propiciar
} 
semiestruturadas com esses profissionais, os quais forneceram, no momento da entrevista, materiais didáticos por eles mesmos produzidos. Assim, os depoimentos resultantes das entrevistas versaram sobre os materiais didáticos, suas finalidades de ensino e seus processos de produção. Dessa forma, as fontes de pesquisa aqui utilizadas consistem em relatos orais de sete professores (as) da educação básica sobre os materiais didáticos por eles (as) produzidos e/ou utilizados.

Uma dessas produções anteriores se dedicou ao contexto específico do CAp/UFRJ, analisando materiais didáticos produzidos por professoras de Ciências daquela instituição, na busca por entender de que forma e com que motivações esses materiais são produzidos, as 'inovações'/tradições curriculares presentes nos mesmos e como a produção dessas 'inovações' curriculares se relaciona com os saberes dos docentes. Nesse sentido, foi possível perceber que dentre as motivações para a produção dos materiais estão a relação entre as professoras do colégio e os licenciandos ${ }^{9}$ de Ciências Biológicas que fazem o estágio de Prática de Ensino na instituição, além da possibilidade de modificar esses materiais com grande rapidez, podendo adaptá-los às diferentes demandas de ensino que cada turma apresenta e à abordagem que a professora deseja privilegiar em sua aula (MORAES, 2015).

Por outro lado, essa pesquisa evidenciou que a produção dos materiais didáticos e das 'inovações' curriculares neles presentes não ocorre de forma consensual, mas envolve conflitos entre representantes da comunidade disciplinar de Ciências do CAp/UFRJ. As 'inovações' mencionadas pelas professoras foram produzidas a partir de um conjunto de tradições, tais como a experimentação, a aplicação do método científico e a valorização de conteúdos muito tradicionais na disciplina. Além disso, também foi possível perceber forte

aos educadores ambientais uma formação que os qualificasse para o desenvolvimento coletivo das Agendas 21 Escolares e de Projetos de Intervenção em Educação Ambiental.

9 Designa os estudantes de Licenciatura em Ciências Biológicas da UFRJ. Muitos licenciandos que cursam a Prática de Ensino em Ciências Biológicas realizam estágio supervisionado no CAp/UFRJ, sob orientação dos professores da Prática de Ensino e dos professores regentes das disciplinas escolares Ciências Biologia, que são docentes responsáveis pelas turmas que os licenciandos acompanham. 
relação entre a atuação dos licenciados e a modificação ou produção de saberes experienciais, uma vez que eles estimulam as docentes do colégio a viverem uma intensa prática reflexiva. Se, por um lado, esses saberes se mostraram atuando na produção de 'inovações' curriculares, por outro a produção de 'inovações' também leva a formação de novos saberes, já que tal produção se dá "no diálogo com os membros da comunidade disciplinar de Ciências do CAp/UFRJ, em um processo de reflexão constante que tem como consequência a construção ou ressignificação de saberes docentes" (MORAES, 2015, p. 106).

A outra produção teve como foco a análise dos conhecimentos que são articulados na produção das práticas curriculares de Educação Ambiental (EA) que foram produzidas no estado do Rio de Janeiro, particularmente as realizadas de modo interdisciplinar em escolas que participaram do Curso de Form-Ação em Educação Ambiental e Agenda 21 Escolar: Elos de Cidadania / Polo Metro X - 2007/2008. Nesse trabalho, diversas questões relacionadas a ações de EA foram analisadas: a sua seleção e inserção no currículo escolar; os sujeitos envolvidos no planejamento e realização dessas ações; as áreas disciplinares envolvidas; a articulação de saberes para a produção dessas ações; as dificuldades encontradas; e a contribuição da formação continuada em EA (MOURA, 2015).

Nesse sentido, a análise dos materiais e depoimentos permitiu compreender que as práticas em EA desenvolvidas pelos (as) professores (as) entrevistados (as) se mostram revestidas de características escolares, sendo dada uma maior importância às finalidades educacionais relativas à EA do que à identificação de conteúdos de ensino relevantes para o seu alcance. Os (as) professores (as) valorizam, em suas ações educativas, o estímulo à observação e percepção das relações entre as pessoas, e destas com o mundo, com o objetivo de promover uma visão crítica por parte dos estudantes frente aos problemas socioambientais. Em parte dos depoimentos, percebe-se uma maior valorização do conhecimento acadêmico e formal em relação ao 
prático e utilitário, um indicativo dos conflitos e disputas por valorização de determinados conhecimentos. Além disso, é possível observar a valorização de ações envolvendo diversas disciplinas, o que evidencia certas ressignificações próprias do contexto escolar. Assim, nota-se que os (as) docentes, imersos em um universo predominantemente disciplinarizado, tendem a inserir as atividades de EA nesse padrão curricular tão fortemente estabelecido no universo escolar (MOURA, 2015).

Ambos os trabalhos, apesar de seguirem focos e caminhos investigativos distintos, se entrecruzam por incluírem em suas abordagens teóricometodológicas as discussões acerca dos saberes docentes, e por analisarem produções curriculares elaboradas por professores (as). Sendo assim, consideramos extremamente fértil a construção de um trabalho que, ao fazer essas produções anteriores conversarem, se aprofunde na reflexão e compreensão do papel que os saberes docentes exercem nos processos de produção de materiais didáticos e, consequentemente, do currículo disciplinar nos contextos escolares.

É importante ressaltar que para a construção da empiria, foram consideradas como fontes: os depoimentos dos (as) sete professores (as) e os próprios materiais por eles disponibilizados. Foi dada total autonomia aos professores (as) para que eles (as) mesmos (as) selecionassem os materiais didáticos sobre os quais as perguntas da entrevista tinham o seu foco principal. Dessa maneira, o principal foco das entrevistas foi em materiais que esses (as) professores (as) utilizam em suas aulas e consideram que são propostas interessantes e relevantes para a sua prática docente, ou que, em sua opinião, representam algo novo e diferenciado para o ensino. Isso possibilitou, com base em Quivy \& Campenhoudt (2005) a construção de uma interpretação dos dados que aceita e reflete a complexidade da realidade, o que permitiu a análise e compreensão das conexões que, sem a mediação do pesquisador, não se estabeleceriam. As entrevistas possibilitaram 0 recolhimento de 
elementos de modo muito aprofundado favorecendo uma proximidade com os entrevistados que amplia as possibilidades analíticas.

Portanto, o caminho investigativo aqui empreendido foi pautado na opção por proporcionar liberdade de escolha para os (as) docentes, de modo que suas preferências e suas vozes pudessem emergir no momento da entrevista. As pesquisadoras puderam, assim, se deparar com dados, materiais e depoimentos totalmente inesperados, já que a seleção das produções curriculares não foi previamente determinada pelo entrevistador. Assim, efetuamos análises associando esses dados às histórias de vida e profissional contadas pelos próprios entrevistados, buscando compreender como a trajetória percorrida e os saberes construídos ao longo de sua carreira no magistério se relacionam com as escolhas e preferências materializadas nas produções curriculares por eles apresentadas. Isso porque, ao permitir que eles falassem dos materiais e que explicassem os motivos de terem selecionado esses e não outros materiais didáticos foram surgindo pistas dos saberes docentes que estão envolvidos com a produção e/ou utilização dos mesmos.

No que diz respeito ao referencial teórico, trabalhamos com a concepção do currículo como construção sócio histórica (CHERVEL, 1990; GOODSON, 1997 e 2012) compreendendo, portanto, que as disciplinas escolares não são imunes às mudanças, mas que estão sujeitas a transformações resultantes de conflitos e disputas entre diferentes subgrupos e tradições (GOODSON, 2012, p.120). No entanto, somamos as ideias desses teóricos às de outros estudos do campo do currículo (FERREIRA, 2005, 2006, 2007 e 2008; GOMES, 2008 e 2013) para embasar nossa escolha por trabalhar com a concepção de que a novidade não implica necessariamente em revoluções curriculares e que, portanto, a 'inovação' não põe sempre fim as antigas práticas e costumes disciplinares.

Assim, escolhemos produzir análises investigativas partindo da premissa de que as 'inovações' curriculares são produzidas por meio da relação com 
'tradições' que não são completamente apagadas, mas que dialogam com as novas propostas, em um processo de incorporação do 'novo' ao 'tradicional'/antigo, representando uma futura "tradição inventada"10 (HOBSBAWM, 198511 apud GOODSON, 2012). Isso porque as novas propostas podem ser tão bem aceitas e incorporadas que acabam se constituindo em tradições curriculares. Além disso, operamos com a ideia de que os (as) professores (as) não são simples reprodutores de um currículo previamente definido, mas representam profissionais capazes de interferir no currículo escolar e que são dotados de um conjunto de saberes característico. Escolhemos, assim, deixar de olhar para o contexto escolar como apenas um espaço de transmissão de conhecimentos gerados espaços institucionais externos, em Universidades e Centros de Pesquisa, mas como um lugar de produção de conhecimentos inerentes a esse contexto (LOPES, 1997). Com isso, reafirmamos que ao desenvolver práticas curriculares, os (as) professores (as) produzem práticas tipicamente escolares, uma vez que são produtores de conhecimentos escolares, deixando marcas próprias em suas ações.

Para discutir sobre os saberes docentes recorremos aos trabalhos de Tardif (2000 e 2012), para o qual os saberes dos professores equivalem a uma mistura de saberes da formação profissional, disciplinares, curriculares e experienciais. Os saberes da formação profissional são aqueles representados pelos saberes pedagógicos e das ciências da educação, transmitidos pelas instituições de formação de professores. Os saberes relativos às outras disciplinas oferecidas pela universidade, mas que não possuem cunho pedagógico são ditos disciplinares, enquanto que saberes curriculares dizem respeito aos programas escolares, objetivos, conteúdos e métodos que os professores devem aprender a aplicar. Por fim, os saberes experienciais são aqueles desenvolvidos no exercício do magistério (TARDIF, 2012). Portanto,

10 O conceito de "tradição inventada" refere-se a "um conjunto de práticas e ritos: práticas, normalmente reguladas por normas expressas tacitamente aceitas; e ritos - natureza simbólica - que procuram fazer circular certos valores e normas de comportamento mediante repetição, 0 que implica automaticamente continuidade com o passado" (HOBSBAWM\& RANGER, 1985 apud GOODSON, 2012, p. 78).

${ }^{11}$ HOBSBAWM, E. Introduction: The invention of tradition. In: HOBSBAWM, E. \& RANGER, T. (orgs.) (1985). The invention of tradition. Cambridge: Cambridge University Press 
com base em Tardif $(2000,2012)$, consideramos os saberes docentes como um amálgama de diferentes conhecimentos e experiências que estão em constante processo de construção influenciados pelos diferentes percursos e caminhos trilhados por cada profissional. Assim, argumentamos que os professores estão constantemente reformulando e produzindo os próprios saberes, e não simplesmente reproduzindo aqueles produzidos por outros.

Além disso, Tardif $(2000 ; 2012)$ argumenta fortemente que os saberes profissionais dos professores são caracterizados como temporais, plurais e heterogêneos, personalizados e situados. O caráter temporal dos saberes docentes se refere ao fato de que um professor aprende a trabalhar à medida que vai exercendo sua atividade docente e, assim, dominando progressivamente os saberes necessários à realização do seu trabalho. Por outro lado, esses saberes são situados, pois são construídos e utilizados em função de uma situação de trabalho particular, de contextos e realidades escolares específicas. E são também são personalizados na medida em que o professor tem uma história de vida, uma cultura, emoções, personalidade, características essas que são absorvidas e passam a fazer parte de sua ação docente.

Outra característica, proposta por esse autor para os saberes profissionais docentes, é a sua pluralidade e heterogeneidade. São saberes que têm sua origem em diversas fontes e buscam atingir distintos objetivos, os quais exigem diferentes tipos de conhecimentos, competências e aptidões. Essas várias fontes são provenientes, por exemplo, "da história de vida individual, da sociedade, da instituição escolar, dos outros atores educativos, dos lugares de formação" (TARDIF \& RAYMOND, 2000, p. 215). O saber do professor também pode ser entendido como social, já que ele não define sozinho seu saber profissional, sendo este fruto de negociação entre diferentes grupos, inclusive os alunos, cada um colocando em jogo seus interesses e suas histórias (TARDIF, 2002 apud SOZO \& POÇAS, 2012). 
Assim, com base nas ideias dos autores aqui apresentados, buscamos compreender os saberes docentes elaborados em meio aos currículos disciplinares de professores da educação básica. Argumentos e exemplos são apresentados, problematizados e discutidos na próxima seção.

\section{SABERES DOCENTES, MATERIAIS didÁticos E PRODUÇão CURRICULAR NAS DISCIPLINAS ESCOLARES}

Para iniciar a apresentação de nossas análises, é importante ressaltar que são aqui discutidos dados empíricos relativos aos depoimentos, a respeito da produção e utilização de materiais didáticos, de sete professores (as) da educação básica. Como já explicitado, tais depoimentos foram tomados em entrevistas que versaram sobre materiais produzidos e utilizados por esses (as) professores (as) em suas atividades de ensino relacionadas a disciplinas escolares como Ciências, Biologia, História e Geografia. Cada professor (a) é designado (a) ao longo desta seção pelas letras A, B, C, D, E, F e G.

Levando em consideração que quatro dos (as) entrevistados (as) são professoras que atuam ou já atuaram recentemente em um colégio de aplicação, ficou evidente a existência de uma forte relação entre os licenciandos que fazem estágio na escola e a produção de materiais didáticos e de saberes docentes. Esses futuros professores expõem as docentes de Ciências do colégio a conhecimentos atualizados, de ponta, da Biologia, "trazendo conteúdo mais fresco" (professora $\mathrm{C}$ ) ${ }^{12}$ suscitam questões do campo educacional para serem discutidas com as professoras, além de estarem constantemente apresentando novas ideias, propostas e possibilidades de abordagem dos conteúdos de ensino, levando as docentes de Ciências a vivenciarem uma frequente e intensa prática reflexiva acerca dos currículos dessa disciplina.

${ }^{12}$ Foram entrevistadas quatro professoras de Ciências do CAp/UFRJ, as quais foram 
A esse respeito, trabalhos anteriores (MORAES, 2015; MORAES \& GOMES, 2015) apontam que os conteúdos mais frescos e "aquela Biologia super recente" (professora B) que os licenciandos trazem consigo se aproximam de saberes de cunho 'disciplinares'. Além disso, tais trabalhos indicam que os licenciandos também expõem as professoras do colégio a 'saberes da formação profissional' ao levantarem novas questões do campo pedagógico para debater com as mesmas. Por outro lado, esses saberes trazidos pelos licenciandos são mediados por saberes experienciais das docentes, produzindo uma relação que acaba "construindo novos 'saberes experienciais' que se refletem na produção de 'inovações' materializadas nos materiais didáticos elaborados" (TARDIF, 2012; MORAES \& GOMES, 2015).

Julgamos interessante revisitar esses trabalhos, pois os mesmos evidenciam o caráter inconcluso do saber docente, ao apontarem a constante possibilidade de construção de saberes da prática pelos professores (as). Assim, em função dos diferentes percursos e vivências da prática vão sendo produzidos ou ressignificados os saberes experienciais dos professores. Nesse sentido, destacamos a proposta de Tardif (2000) de que os saberes desses profissionais são caracterizados por serem temporais, plurais e heterogêneos, personalizados e situados. Sendo, portanto, temporais, esses saberes estão sendo constantemente construídos e reconstruídos no decorrer da atividade docente, já que os professores vão progressivamente dominando, desenvolvendo e aprimorando os saberes necessários à realização do seu trabalho.

$\mathrm{Na}$ análise que aqui apresentamos, dedicamos especial atenção ao caráter personalizado do saber docente e apresentamos evidências que explicitam a existência de uma estreita relação entre esses saberes e os rumos do currículo disciplinar. Apoiadas em Tardif (2000), entendemos que esses saberes são personalizados na medida em que o professor tem uma história de vida, uma cultura, emoções, personalidade, características essas que são absorvidas e passam a fazer parte de sua ação docente. Tem-se, portanto, que diferentes 
trajetórias e experiências profissionais vão contribuindo para definir e caracterizar o conjunto de conhecimentos de determinado docente.

A esse respeito destacamos o estudo dirigido ${ }^{13}$ produzido pela professora $\mathrm{C}$ e intitulado 'o modelo atômico de Dalton: moléculas e reações químicas'14. Tratase de um material que trabalha a temática 'modelos atômicos' e que utiliza a fotossíntese para exemplificar o que ocorre com as moléculas em uma reação química. Uma das atividades do referido material intitula-se 'fábrica de moléculas' e convida os alunos a montarem modelos de moléculas envolvidas na reação da fotossíntese usando, para isso, massinha e bolinhas de isopor. Em outro estudo dirigido nomeado 'terrário e reações químicas', a professora também aborda o conteúdo reações químicas a partir do processo da fotossíntese. No entanto, de acordo com a própria professora, um grande diferencial desse material é dar especial atenção ao aperfeiçoamento da escrita científica por parte dos alunos. Assim, em determinado momento é solicitado que os alunos montem tabelas com os resultados observados e que produzam um relatório do experimento do terrário, no qual constem: introdução, objetivos do experimento, hipóteses, desenvolvimento, resultados, discussão e fonte consultada.

De acordo com a entrevistada, a ideia de trabalhar terrário no 9a ano surgiu com a professora A e a partir daí, esse material foi sendo reformulado:

Eu peguei essa ideia dela e fui trabalhando, trazendo outras coisas da minha vivência. Eu tenho, por exemplo, hoje, estou até no Doutorado estudando isso, essa questão da leitura e escrita no ensino de Ciências, sabe? Os meninos que têm muita dificuldade de leitura e escrita, como é que eles conseguem aprender Ciências

\footnotetext{
13 Os estudos dirigidos equivalem a materiais impressos que visam trabalhar determinados conteúdos escolares associando textos, imagens e gráficos com perguntas e/ou atividades a serem respondidas pelos alunos (MACIEL, ET. AL., 2014, p. 70). Assim, não se tratam de listas de perguntas que buscam revisar algum conteúdo já trabalhado pelo professor, mas se constituem em materiais que funcionam "como uma espécie de roteiro de aula, onde imagens, textos e atividades vão guiando o aluno para a compreensão de determinado conteúdos (MORAES, 2015, p. 44), estimulando a construção ativa de conteúdos a partir dos desafios propostos.

${ }_{14}$ Todos os materiais didáticos aqui analisados podem ser disponibilizados por meio de contato com o NEC/UFRJ.
} 
nesse contexto, como é que Ciências pode ajudar a ler e escrever melhor. Então eu usei esse trabalho do terrário para investir nisso (professora C).

Dessa forma, o referido material apresenta um grande investimento nas estratégias de ensino que possibilitem o desenvolvimento da leitura e escrita no ensino de Ciências. Tal investimento estaria relacionado, de acordo com a própria professora, com conhecimentos que a mesma vem adquirindo em seu doutorado, já que a leitura e escrita científicas vêm sendo alvo de estudo da mesma. Assim, sua experiência em processos de formação continuada parece estar contribuindo para a construção de saberes docentes que a permitem perceber essa demanda específica dos alunos, levando-a a investir em um novo foco e abordagem para a temática curricular trabalhada. Percebe-se 0 quanto saberes personalizados dessa professora vem interferindo na sugestão de novas propostas de abordagens curriculares, que se materializaram na produção didática elaborada.

Portanto, fica evidente a autonomia com que o docente pode interferir no currículo disciplinar muito sobre influência dos saberes que possui e, com isso, pode contribuir para a produção de 'inovações' curriculares. Defendemos que 'inovações' são produzidas, pois compreendemos que as novidades dialogam com tradições curriculares já existentes que se configuram como conhecimentos disciplinares a ensinar, e assim, vão construindo novas propostas que podem, futuramente, se consolidar como tradições (GOODSON, 2012; FERREIRA, 2005, 2006, 2007 e 2008; GOMES, 2008 e 2013). Dessa forma, a nova proposta da professora $\mathrm{C}$, de investir na leitura e escrita científicas, não surge do nada e nem provoca revoluções que apagam as tradições já consolidadas na disciplina escolar Ciências. A novidade valorizada pela docente parte das temáticas 'modelos atômicos' e 'reações químicas', muito tradicionais na disciplina escolar Ciências do $9^{\circ}$ ano do Ensino Fundamental, e assim, vão sendo construídas 'inovações' que se concretizam nos materiais didáticos apresentados. 
Outro exemplo que explicita a influencia que saberes docentes personalizados exercem sobre as escolhas curriculares, é perceptível nos materiais fornecidos pela professora $A$, os quais apresentam atividades que recorrem à experimentação e a abordagens da história da ciência. Encontra-se explicação para as preferências materializadas nas produções curriculares da professora A quando nos atentamos para sua trajetória acadêmica e profissional, já que ela fez bacharelado em genética na UFRJ e doutorado na biofísica, em biologia molecular, tendo uma longa história de proximidade com atividades experimentais. Nas palavras da própria professora, o gosto pela história da ciência e pelos experimentos "vem da minha formação, da minha formação acadêmica".

O investimento na história da ciência também foi muito valorizado pela professora $\mathrm{B}$, já que absolutamente todos os materiais fornecidos pela mesma se utilizam dessa abordagem para trabalhar os conteúdos curriculares fotossíntese, características dos seres vivos e ondas sonoras e luminosas. É curioso perceber que, apesar de tanto a professora $A$ quanto a $B$ reconhecerem a história da ciência como algo que deve receber destaque, os caminhos e experiências que levaram as mesmas a realizarem essa escolha são distintos. No caso da professora B, focar na história da ciência é, de acordo com a mesma, conseqüência de dois fatores, sendo eles um livro sobre a história da fotossíntese que a mesma leu quando estava estudando para o concurso de ingresso no CAp/UFRJ, e a regência de uma amiga sua na época da licenciatura, na qual a história dos conhecimentos sobre os átomos foi a abordagem para o ensino:

Então acabei fazendo essa proposta muito impactada por essas referências que eu tive, tanto da licenciatura, quando eu fui estagiária, quanto dessa leitura que eu fiz sobre a fotossíntese (professora B).

Percebe-se, assim, que as seleções curriculares, em torno do que e como ensinar, dessas professoras são grandemente impactadas pelas experiências e percursos vividos por cada uma e pelos saberes que as mesmas vêm 
construindo em sua trajetória profissional. Dessa forma, entende-se que a produção de 'inovações' curriculares é influenciada "pelo conjunto de saberes que o professor foi adquirindo no decorrer de sua trajetória pessoal e profissional, dependendo, por exemplo, da instituição de ensino superior na qual se formou, dos caminhos percorridos na formação continuada e das experiências docentes já vivenciadas" (MORAES, 2015, p. 99).

O exemplo da professora $D$, no entanto, nos permite perceber que os saberes personalizados dos docentes não são consequência somente de experiências oriundas da formação inicial e continuada. Isso porque um dos materiais fornecidos pela docente intitula-se 'relatório montagem de modelo de célula', o qual foi produzido, de acordo com a professora, por influência de uma aula que a mesma teve quando ainda estava na escola:

... foi uma prática que eu não inventei, que uma professora fez quando eu era aluna, que era montar um modelo de célula comestível, que ela montou com gelatina e confeitos, tipo jujuba, bombom (professora D).

Assim, as escolhas concretizadas nesse material refletem conhecimentos que foram produzidos antes mesmo do início da formação para a docência, o que reforça o entendimento de que a história de vida de cada profissional contribui para a definição do conjunto de seus saberes docentes, saberes esses personalizados.

Do mesmo modo que Moraes (2015), Moura (2015) também evidenciou que os saberes docentes são personalizados e situados, pois sofrem interferências das diferentes trajetórias e experiências profissionais contribuindo para definir e caracterizar o conjunto de conhecimentos de determinado docente (TARDIF, 2000). Por exemplo, isso foi percebido no depoimento da professora $E$ ao citar materiais e vídeos adquiridos ao longo de sua trajetória acadêmica e profissional, usados por ela até os dias atuais.

Eu levei materiais do Curso para a minha prática. Algum vídeo, alguma música. Por exemplo: a música Earth song do Michael 
Jackson. Eu trabalho com ela até hoje. Eu uso quando tem alguma coisa de meio ambiente (Professora E).

A docente tece comentários sobre o referido vídeo com o qual teve contato durante o Curso em 2008, a construção de um aquecedor de água com luz solar que foi aprendido durante uma oficina do Programa Elos em 2009, assim como DVDs e jogos ganhos em outros cursos e comprados em lojas que são utilizados em suas aulas.

\begin{abstract}
Olha quanta coisa tem. Rio +20 , desafio de sustentabilidade. É um vídeo que eu assisti lá e gostei tanto que eu trouxe e trabalhei com os alunos. Esse é de mudanças climáticas. Só fala de aquecimento global, efeito estufa. Esse aqui é de sexualidade. Esse aqui é de outro projeto da Petrobrás, o Conpet na escola. (...) Uma coisa que eu trouxe. Confesso que eu ainda não trabalhei na escola. Eu acho que ficou um pouquinho difícil para eles. O jogo da Terra. Não sei se você conhece. A gente trabalha a carta. Quando eu vi o jogo, eu não me contentei e comprei. Eu comprei isso no Aterro do Flamengo no Rio +20 . O pessoal estava vendendo lá. Greenpeace - mudanças de clima, mudanças de vida. (...) É, eu vou catando na internet. Alimentos - desperdícios e alimentos. Esse é do Boticário mudanças climáticas e boas práticas. Kit ecologia, meio ambiente. Pen drive do professor do Curso da Agenda 21, eu te falei que eu ainda tenho. Esse aqui é de lá, do ELOS (Professora E).
\end{abstract}

A partir dessa fala da docente pode-se reforçar a ideia de que seus conhecimentos são personalizados e situados, pois são a sua história de vida, as trajetórias acadêmicas e profissionais que constroem e definem o conjunto de saberes e experiências que passam a fazer parte de sua ação docente.

Também é possível identificar indícios de um saber personalizado e situado na fala do professor F. As diversas ações deste professor são bastante interessantes na medida em que refletem fortemente as suas experiências de formação ao longo de sua vida profissional ${ }^{15}$, principalmente as de sua

15 O professor E é licenciado em Ciências Biológicas pela Universidade Federal do Rio de Janeiro (UFRJ) e possui Pós-Graduação Latu Sensu em Gestão Ambiental na UERJ. Além disso, é especialista em Ensino de Ciências e Biologia pelo Conselho Regional de Biologia. Há 23 anos leciona aulas de Biologia na Rede Estadual do Rio de Janeiro, mas antes disso já atuava em Ensino de Ciências no Projeto Fundão Biologia - UFRJ. É válido ressaltar que este docente participou de todas as versões do Curso de Form-Ação em Educação Ambiental e Agenda 21 Escolar: Elos de Cidadania / Polo Metro X - 2007/2008. 
continuidade nas atividades de formação do Programa ELOS ao longo de sete anos:

\begin{abstract}
É muito variado. Eu gosto de trabalhar com a saúde ambiental como eu falei para você. A saúde ambiental dá pano para mangas. Você não fica só em uma temática de um problema ambiental. De um rio, de uma lagoa ou de uma poluição atmosférica. Você abre esse leque e eles vão se empenhando e fazendo. As oficinas demonstram bem isso. A gente trabalhou com violência, gênero, a gente trabalhou com a questão da prevenção, a proteção, da promoção da saúde, nós trabalhamos a questão da qualidade da água, trabalhamos a questão da grafitagem para dar um recado para a questão ambiental, a pesquisa das plantas purificadoras. Então, é um leque bem abrangente. Eu gosto do tema saúde ambiental, porque dentro dele eu posso colocar várias coisas e eu posso diversificar sem grandes problemas. Até agregar outras propostas de parceria dentro desse contexto (Professor F).
\end{abstract}

Fica claro que este professor é detentor de visão ampla e complexa sobre as possibilidades de se trabalhar com a EA no ambiente escolar, já que vislumbra que esta deve ter uma faceta socioambiental, sendo isso identificado por ele como um aprendizado vivenciado no Programa Elos de Cidadania.

Porque o próprio programa é socioambiental. Se é socioambiental você tem que trabalhar a questão social e ambiental. $E$ a questão social envolve a questão da saúde e da autoestima do indivíduo, o reconhecimento do espaço, da importância dele no espaço como agente de modificação. Para mim é uma temática bem interessante para fomentar as ações que eu pretendo fazer (Professor F).

Portanto, os trechos do depoimento do professor E permitem identificar uma forte influência de sua trajetória, tanto da formação inicial como da formação continuada, em sua capacidade de articulação de conhecimentos para os processos de produção e utilização de materiais didáticos no contexto do ensino de Biologia na escola. Em outras palavras, podemos defender que também para este professor os saberes docentes são personalizados e situados. 
Ainda com base em Tardif (2012), Moura (2015) identificou fortemente a presença de saberes caracteristicamente disciplinares nos depoimentos e materiais didáticos produzidos pelas professoras $\mathrm{E}^{16}$ e $\mathrm{G}^{17}$. Por exemplo, em alguns textos apresentados pela professora $\mathrm{G}$, percebe-se claramente a sua aproximação com a organização curricular da disciplina escolar Geografia, que caracteriza a sua principal formação. Esta professora demonstra em seus materiais, que ao selecionar tipos determinados e específicos de textos para suas atividades de ensino, acaba por prestigiar um conhecimento de natureza mais acadêmica e formal, em detrimento de aspectos mais práticos e utilitários. Isso remete às contribuições de Goodson (2012) para a existência de tipos de conhecimentos que constituem determinadas propostas de currículo, tendo isto relação com a origem social e o destino ocupacional dos estudantes. Segundo este autor, para as classes alta e média, em geral são selecionados conhecimentos para a vida acadêmica ou profissional, submetidos às definições sobre conhecimento válido, formuladas pelos estudiosos das universidades. Enquanto para as classes consideradas baixas são ministrados saberes de caráter utilitário, correlacionados a ocupações não profissionais.

Desse modo, no texto ' $\mathrm{O}$ ciclo hidrológico e a distribuição dos recursos hídricos', disponibilizado pela referida professora F, é possível identificar uma aproximação com a Geografia física a partir de uma apresentação do ciclo hidrológico e da distribuição espacial da água nos continentes. O mesmo foi identificado nos textos fornecidos pela professora $E$, havendo aproximações marcantes com a sua área acadêmica de referência, a Biologia. Sendo assim, ao analisar um texto, produzido por esta professora, sobre Dia Mundial do Meio Ambiente 2010, pode-se identificar facilmente alguns termos característicos da área de Biologia, como: biodiversidade, espécies em extinção, teia alimentar e preservação ambiental. Em ambos os casos, essas professoras prestigiam

\footnotetext{
${ }^{16}$ A professora D possui Graduação em Ciências Biológicas na UFRRJ e Pós-graduação em Análises Clínicas pela Universidade Sousa Marques e em Psicopedagogia pela Universidade Cândido Mendes.

${ }^{17}$ A professora $\mathrm{F}$ tem curso de Graduação em História e Pedagogia na Universidade Santa Úrsula e depois em Geografia na Universidade do Estado do Rio de Janeiro, tendo, portanto, uma formação ampla e diversificada.
} 
mais fortemente o conhecimento acadêmico e formal quando comparado com o prático, cotidiano e utilitário. Isso é indicativo dos conflitos e disputas por valorização de determinados conhecimentos que são parte da constituição da organização dos currículos escolares, conforme discutido por Goodson (2012) em seus estudos sobre as disciplinas escolares.

Partindo desses diversos exemplos aqui apresentados, sobre o fazer docente dos professores (as) E, F e G, Moura (2015) também pontua que cada professor (a), ao desenvolver suas ações de ensino em EA com os diversos sujeitos de cada comunidade escolar, com características particulares, constrói diferentes saberes docentes, especificamente diferentes saberes experienciais. Isso fica claro, por exemplo, com o depoimento da professora $E$ que afirma que muitas atividades surgem sem planejamento prévio, ou seja, a partir das situações que surgem inesperadamente no cotidiano da docência. Ela relata uma situação que ocorreu na escola com um aluno cadeirante que deixou de freqüentar a escola, porque sua cadeira de rodas havia quebrado. Ao tomar ciência da situação, a professora realizou uma campanha de recolhimento de lacres de latas de refrigerante e conseguiu verba para resolver a situação. Portanto, esse processo não é apenas individual, mas também é construído coletivamente a partir das interações que esse profissional faz com outros atores educativos e seus alunos, tendo um caráter social, pois é fruto de negociações entre diferentes grupos em um contexto específico, carregando marcas do seu objeto de trabalho que são os alunos (TARDIF, 2000).

Todos os exemplos problematizados nesta seção ajudam a corroborar a defesa de que os saberes dos professores são personalizados na medida em que refletem sua trajetória acadêmica e profissional, os caminhos trilhados e sua história de vida, particularidades essas que vão contribuindo para constituir o 'ser' docente de cada um, caracterizando seus saberes. Mais do que isso, consideramos que os dados apresentados evidenciam o quanto esses saberes personalizados influenciam na valorização de novas abordagens e enfoques curriculares, que se materializam nos materiais didáticos produzidos por esses 
professores e, consequentemente interferem significativamente no currículo escolar produzindo novos sentidos para o que é ensinado nas disciplinas escolares. Reforçamos, no entanto, que entendemos que essa interferência curricular se dá em uma perspectiva de "invenção de tradições" (HOBSBAWM, $1985^{18}$ apud GOODSON, 2012), já que as novidades não revolucionam por completo o currículo disciplinar, apagando antigas tradições curriculares, mas sim dialogam com essas resultando na construção de novas tradições.

\section{CONSIDERAÇõES FINAIS}

$\mathrm{Na}$ seção anterior problematizamos análises de depoimentos de sete professores (as) que exercem suas atividades profissionais em escolas da educação básica ensinando áreas disciplinares como Ciências, Biologia, Geografia e História. Partindo de discussões teóricas sobre os conhecimentos disciplinarizados, as 'inovações' curriculares e os saberes docentes, procuramos estabelecer relações significativas entre os processos de produção de materiais didáticos e as diversas e complexas características da natureza personalizada e situada dos saberes articulados pelos professores em suas práticas curriculares. Desse modo, a partir dos dados aqui analisados é possível argumentar que: (i) é diversa e complexa a integração de saberes dos professores quando estes estão envolvidos em processos de produção e utilização de materiais didáticos em suas atividades de ensino; (ii) a formação disciplinar permeia a construção de finalidades para o ensino e a produção dos materiais didáticos empreendidas por esses profissionais; e (iii) os saberes docentes detêm muitas características das experiências de vida dos professores.

Assim, partindo de nossas análises e com base em Tardif \& Raymond (2000), defendemos os saberes profissionais dos (as) professores (as) como sendo

\footnotetext{
${ }^{18}$ HOBSBAWM, E. Introduction: The invention of tradition. In: HOBSBAWM, E. \& RANGER, T. (orgs.) (1985). The invention of tradition. Cambridge: Cambridge University Press.
} 
temporais, plurais e heterogêneos, personalizados e situados. Ao exercerem o seu trabalho, os (as) professores (as) aprendem a trabalhar e, aos poucos, vão dominando os saberes necessários para o exercício de sua profissão. Em outras palavras, a riqueza de sua formação pode estar localizada nas diversas fontes a partir das quais esses (as) profissionais vão construindo o seu saber, seja na trajetória de vida em sociedade, nas instituições escolares em que trabalham e/ou em que se formam, nas relações que tecem com outros atores educativos, quer dizer, em todos os diversos espaços/tempos formativos.

Mais ainda, compreendemos o saber docente como um amálgama de saberes que provêm de sua formação, sendo eles: saberes da formação profissional, saberes disciplinares, curriculares e da experiência. Porém, evidenciamos e reforçamos a ideia de que o processo de construção desses saberes não se dá de forma individual e isolada sendo, na verdade, uma construção coletiva a partir das interações que cada professor vivencia com outros atores educativos e com os seus alunos (TARDIF, 2012). Desse modo, podemos afirmar também que reconhecemos os processos de produção curricular nas instituições de educação básica como espaços/tempos escolares de produção, transformação e mobilização de saberes próprios dos docentes e frutos de sua trajetória de vida. Portanto, defendemos a ideia de que nesses espaços ocorre reorganização, reestruturação e recontextualização dos conhecimentos com base em diversas referências (LOPES, 1997).

Concluindo, acreditamos que, ao discutir os saberes docentes e mostrar sua relação com os materiais didáticos analisados e as preferências curriculares neles concretizadas, este trabalho pode contribuir para evidenciar e reforçar o quanto o conjunto desses saberes influencia nas possíveis abordagens e enfoques curriculares concretizados nos materiais didáticos elaborados, interferindo diretamente no currículo escolar. E nesse sentido, defendemos que os saberes personalizados dos docentes influenciam no currículo na medida em que contribuem para a produção de 'inovações', já que as novas propostas e abordagens dialogam com as tradições já existentes, construindo novas 
tradições que associam o 'novo' ao 'antigo'. Consideramos assim, que a análise aqui discutida é potente para justamente associar os saberes docentes à produção de novidades curriculares, evidenciando o poder que esses profissionais possuem de interferir nas decisões curriculares.

\section{REFERÊNCIAS}

CHERVEL, A. História das disciplinas escolares: reflexões sobre um campo de pesquisa. Teoria e Educação (2). Porto Alegre, 1990. 177-229.

FERREIRA, M. S. A História da Disciplina Escolar Ciências no Colégio Pedro II (1960-1980). Tese de Doutorado. 212 p. Rio de Janeiro: FE/UFRJ, 2005.

FERREIRA, M. S. Currículo e docência no Colégio Pedro II: analisando as influências institucionais na definição dos rumos da disciplina escolar Ciências. In: Anais do XIII Encontro Nacional de Didática e Prática de Ensino. Recife: UFPE, 2006.

FERREIRA, M. S. Investigando os rumos da disciplina escolar Ciências no Colégio Pedro II (1960-1970). Educação em Revista (UFMG), v. 45, p. 127144, 2007.

FERREIRA, M. S. Currículo de Ciências: investigando as ações do Centro de Ciências do Estado da Guanabara, Brasil, nos anos de 1960/70. In: Anais do VII Congresso Luso-Brasileiro de História da Educação. Porto, p. 1-7, 2008.

GOMES, M. M.Conhecimentos ecológicos em livros didáticos de Ciências: aspectos sócio-históricos de sua constituição. Tese de Doutorado, 250 p. UFF, Niterói-RJ. 2008.

GOMES, M. M.; SELLES, S. E.; LOPES, A. C. Currículo de Ciências: estabilidade e mudança em livros didáticos. Educação e Pesquisa, São Paulo, v. 39, n. 2, p. 477-492, abr./jun. 2013.

GOODSON, I. F. A Construção Social do Currículo. Lisboa: Educa, 1997.

GOODSON, I. F. Currículo: Teoria e História. 12. ed. - Petrópolis, RJ: Vozes, 2012.

LOPES, Alice Casimiro. Conhecimento escolar em Química - Processo de mediação didática da Ciência. Química Nova na Escola, 1997, p. 563-568.

MACIEL, C. M.; PORTO, F. S.; LIMA, I. V.; MATOS, M.; VILELA, M. L.; RIOS, N. Formação docente em Ciências Biológicas no Cap-UFRJ: refletindo sobre tradições e inovações. In: Formação docente, pesquisa e extensão no CApUFRJ: entre tradições e invenções. 200p. Rio de Janeiro: Editora FGV, 2014. 
MORAES, B. G. S. de. Materiais didáticos como 'inovações' curriculares: entre saberes docentes e 'tradições' da Disciplina Escolar Ciências. Dissertação de mestrado, 129 p. Rio de Janeiro: FE/UFRJ, 2015.

MORAES, B. G. S. de.; GOMES, M. M. Entre saberes docentes e 'inovações' curriculares em ciências: do estágio supervisionado da Prática de Ensino no CAp/UFRJ. VII Encontro Regional de Ensino de Biologia da Regional RJ/ES. 2015.

MOURA, N. C. de. Currículos escolares: a articulação de saberes em práticas de educação ambiental. Dissertação de mestrado, 166 p. Rio de Janeiro: FE/UFRJ, 2015.

QUIVY, R.; CAMPENHOUDT, Luc Van. Manual de Investigação de Ciências Sociais, 4⿳亠丷厂 edição, outubro de 2005.

TARDIF, M. Saberes profissionais dos professores e conhecimentos universitários Elementos para uma epistemologia da prática profissional dos professores e suas consequências em relação à formação para o magistério. Revista Brasileira de Educação, Jan/Fev/Mar/Abr, 2000, no 13;

TARDIF, M. Saberes docentes e formação profissional. 13. ed. - Petrópolis, RJ: Vozes, 2012.

TARDIF, M.; RAYMOND, D. Saberes, tempo e aprendizagem do trabalho no magistério. Educação \& Sociedade, ano XXI, n 73, dezembro, 2000. 